\title{
Effect of Pre-stretching Process on Quenching Residual Stress of EW75 Magnesium Alloy
}

\author{
Xinggang $\mathrm{LI}^{\mathrm{a}}{ }^{*}$, Hongbin LIAO, Minglong MA ${ }^{\mathrm{b}}$, Jiawei YUAN, Ting LI, Dongjie \\ CHEN, Kui ZHANG
}

State Key Laboratory of Non-ferrous Metals and Processes

General Research Institute for Non-ferrous Metals, Beijing, 100088

axg1218@grinm.com, ${ }^{\mathrm{b}}$ maminglong@grinm.com

\begin{abstract}
Keywords: EW75 magnesium alloy, Pre-stretching; microstructure, mechanical properties, residual stress

Abstract. This paper studies the effect of pre-stretching process on the residual stress and mechanical properties of EW75 magnesium alloy by OM and mechanical tests, etc. The results show that the bend deformation caused by the release of quench residual stress increases after machining into the pre-stretching sample. For the pre-stretching rate of $1.0 \%, 1.5 \%, 2.0 \%$ and $2.5 \%$, the strain stress curves are similar and rebound phenomenon happens after unloading and varying degrees of twin deformation happens both in the surface and the core. When the deformation rate is $1 \%$, the ultimate tensile strength of the material increases $20 \%$, the yield strength increases $43 \%$, while the fracture elongation reduced $30 \%$ subsequently. As the pre-stretching rate continues to increase, the yield strength, ultimate tensile strength and elongation are little changing.
\end{abstract}

\section{Introduction}

Residual stress has impacts on the statically strength, fatigue property and corrosion property of the material and it will produce during the solidification and cooling, thermal processing and machining process. In recent years, for the magnesium alloy, study focused on the magnesium matrix composites and stress production during welding process. Stress measurement technology for magnesium alloy and the effect of residual stress on fatigue and corrosion resistance properties are also studied [1,2]. There is no report or publication about the stress relief process until now. Magnesium alloy, especially $\mathrm{Mg}-\mathrm{RE}$ alloy, has a large temperature difference between the surface and center during rapid cooling process because of its low thermal conductivity, and great non-uniform plastic deformation happens while it has a large thermal expansion coefficient, thus, internal stress produces and quench cracking happens frequently or causes final residual deformation in the ends [3]. $\mathrm{Mg}-\mathrm{RE}$ alloy has a relatively high yield ratio, the releases residual stress violent, sometimes the alloy may even crack because of this [4]. In addition, the aerospace industry requires high dimensional accuracy of the material. But the residual deformation will reduce material utilization and increase production costs [5]. Therefore, it is a necessary prerequisite to develop and apply Large-scale structure of magnesium alloy to control of residual stress in magnesium alloy strictly. This article is focused on the EW75 magnesium alloy in solid solution state. By studying the influence of pre-stretching process on the microstructure and properties of the alloy, we get an effective way to eliminate the residual stress of the alloy, which provides the necessary experimental data for the utilization of magnesium alloy, and expands the scope of application of magnesium alloys.

\section{Research methods}

Extruded plate of EW75 magnesium alloy is the as-received material and it will be machined into the pre-stretching sample after solution heat treatment. And the samples are separated from intermediate by wire cutting to measure the initial deformation. Pre-stretching implements in tensile test machine and pre-stretching rate is $1.0 \%, 1.5 \%, 2.0 \%$ and $2.5 \%$. The strain-stress curves are record in order to 
investigate the deformation rules during stretching. After pre-stretching process, the microstructure of the alloy is observed and the mechanical properties of the alloy are measured with standard tensile test sample.

\section{Results and analysis}

Fig. 1 shows the macro morphology of the pre-stretching specimen before and after machining. It can be seen that the states of stress distribution are consistent before and after, but deformation increases (as shown in Table 1). The reason is that the stress distribution in new edge, which distributes laminar initial, is different from the before and had a smaller restriction on deformation. So the later period of the research will use the residual deformation as the initial deformation.

\section{(a)}

\section{(b)}

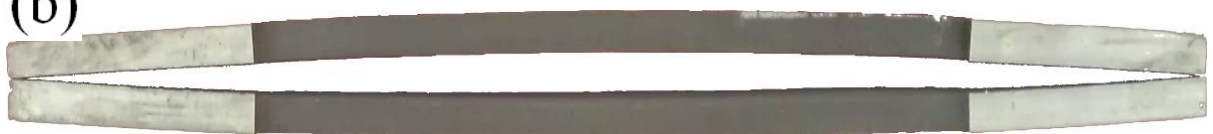

Fig. 1. The macro morphology of the specimen before and after machining (a) : before machining ; (b) : after machining

Table 1. Comparison of residual deflection and cross section area of pre-stretching specimen before and after machining

\begin{tabular}{lcc}
\hline & Before & After \\
\hline $\operatorname{deflection}(\mathrm{mm})$ & 8.48 & 11.60 \\
\hline
\end{tabular}

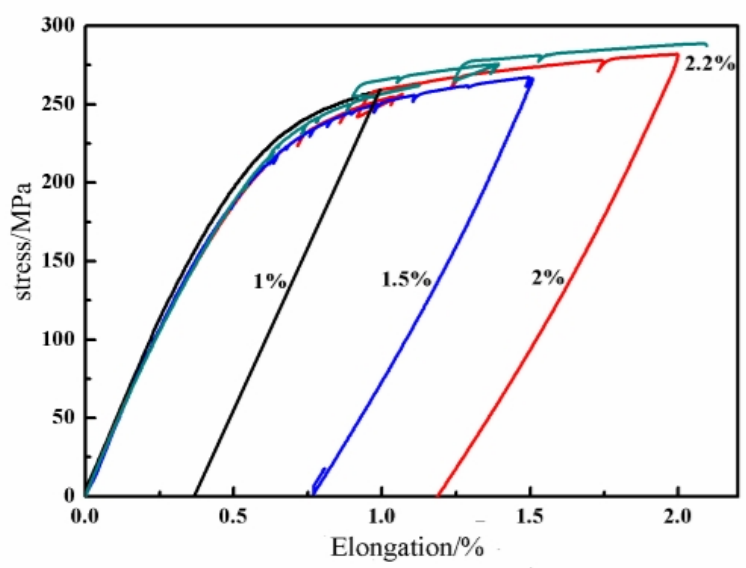

Fig. 2. The loading and unloading curves of samples in different deformation

Table 2. The elastic rebound rate of the samples after unloading in different deformation

\begin{tabular}{cccc}
\hline The amount of pre-stretching $(\%)$ & 1 & 1.5 & 2 \\
\hline Elastic rebound $(\%)$ & 0.6 & 0.72 & 0.8 \\
\hline
\end{tabular}

Fig. 2 shows the loading and unloading curves in different deformation rate. As can be seen, recovery occurred in every curve, which is due to holder and slippage of samples in the stretching process. After barbed jig biting specimen, plastic deformation occurs in bitten portion during stretching. So the payload has not been fully applied to the specimen, which appears emergency response of the stress and strain on the stress-strain curve. Under the conditions of a $2.5 \%$ pre-stretching, sample fractures at $2.2 \%$. 
In pre-stretching process, all of the samples in different deformation rate have the similar stress-stain relations. After unloading, rebound occurs. The rebound ratios of the samples after unloading in different deformation are shown in table 2 . It can be seen that when the deformation is $1 \%$, the rebound is $0.6 \%$, with an increase in the rate of pre-stretch, rebound rate increases and when the deformation rate increases to $2 \%, 0.8 \%$ rebound. This occurs because the internal discontinuity of material during pre-stretching process, mainly caused by the residual stress. Then different parts cannot reach the yield limit at the same time. When a small amount of deformation, parts of the region have not yet reached the yield limit, so rebound small. As the tensile deformation increases, the uneven distribution of the initial stress caused by the residual stress in material weaken and more parts of the material reach yield limit, so rebound more after unloading. When the entire material has reached the yield limit, how much material rebounds is determined by the material nature.

Fig. 3 shows relationship between residual deflection and deformation. As we can see, the residual deflection decreases as the deformation rate increases. Initial residual deflection is $3.5 \mathrm{~mm}$, when the deformation reaches $2 \%$, the residual deflection is $0.55 \mathrm{~mm}$, eliminating by $85 \%$. This proves that pre-stretching method can effectively eliminate the residual stress of quenched magnesium alloys.

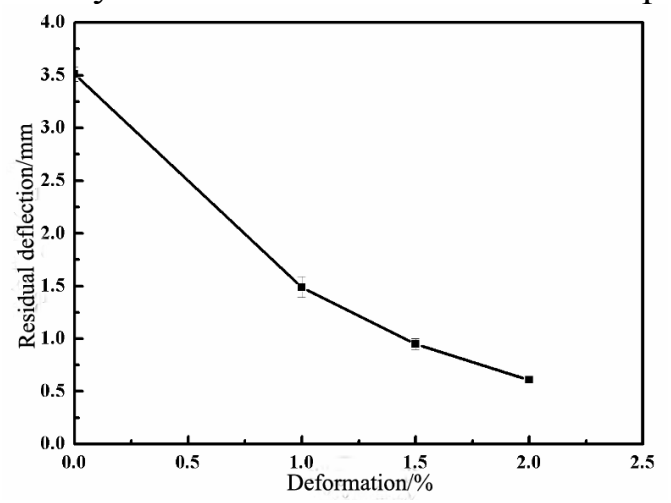

Fig. 3. Relations between residual deformation and pre-stretching
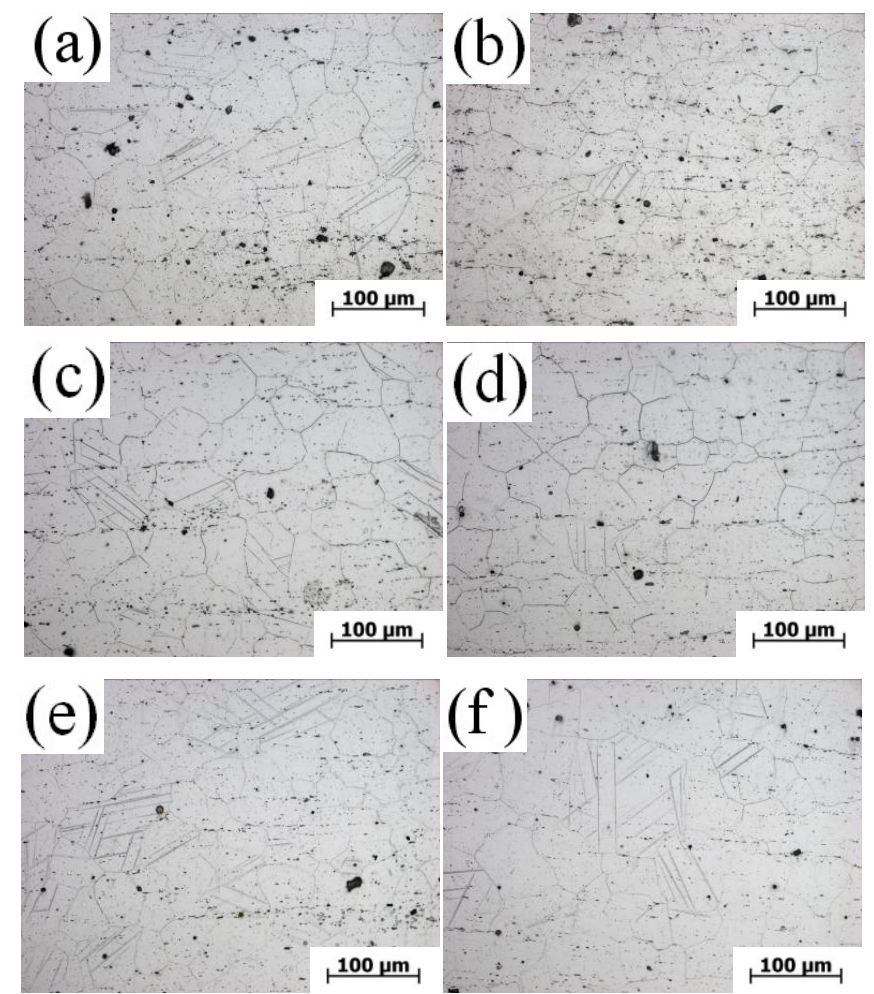

Fig. 4. The influence of pre-stretching on the microstructure of materials

(a) : $1 \%$ in the middle ; (b) : $1 \%$ in the side ; (c) : $1.5 \%$ in the middle ;

(d) : $1.5 \% 1 \%$ in the side ; (e) : $2 \%$ in the middle ; (f) : $2 \% 1 \%$ in the side ; 
The influence of pre tension deformation on the residual stress is studied, and it is found that the pre-stretching process can effectively eliminate the residual stress. But for material application, the pre-stretching is to reduce the residual deformation based on the keeping of structure and mechanical properties of the alloy. Therefore, the microstructure and mechanical properties of the materials after the pre-stretching studied.

Fig. 4 shows the influence of the rate of pre stretching on the microstructure of the material. It is found that there are different degrees of twinning in surface and the center in all deformation.

Due to the Basinger effect, the resistance of the material to further deformation will increase in the same direction as the pre-deformation. It can be seen that when the deformation rate is $1 \%$, the tensile strength of the material increases by $20 \%$, the yield strength increases by $43 \%$, while the fracture elongation decreases by $30 \%$. Subsequently, the yield strength, tensile strength and elongation of the yield strength are not changed with the increase of the pre-stretch rate. The reason is that the speed of dislocation piling up and unlocking is depending on the deformation rate. Therefore, in certain deformation rate conditions, alloy performs higher strength than the initial state, but more than $1 \%$, mechanical properties changes little (Fig. 5).

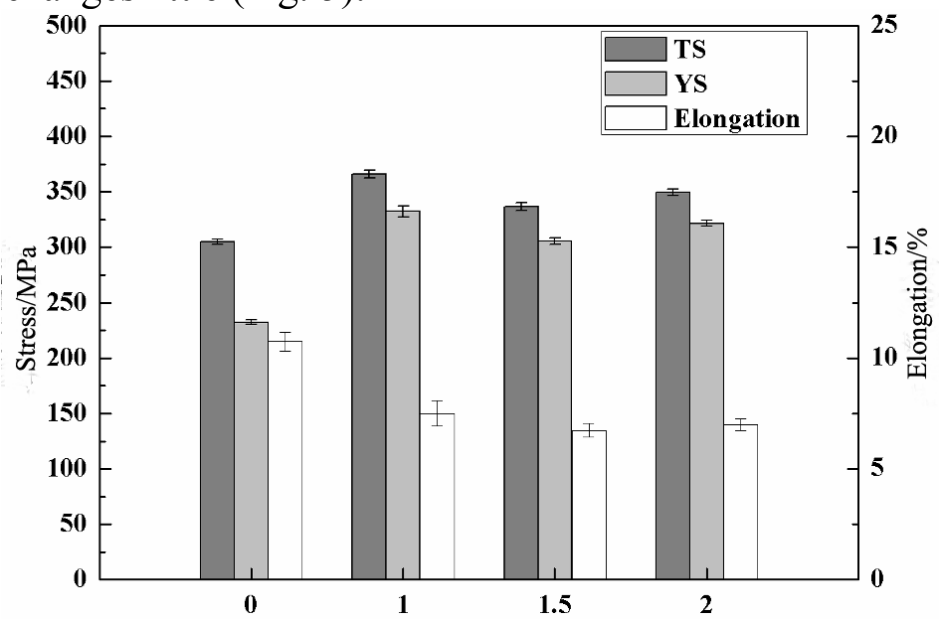

Fig. 5. Mechanical properties after pre-stretching

\section{Summary}

1) The internal stress distribution keeps consistent before and after sample machining, but the deformation caused by the release of internal stress increases. The reason is that the stress distribution in new edge, which is laminar initial, is different from before and has a smaller restriction on deformation..

2) In pre-stretching process, all of the samples in different rate have the similar stress-stain curves. After unloading, rebound occurs. When the deformation is $1 \%$, the rebound rate is $0.6 \%$, with the increase of the amount of pre-stretching, the rebound rate increases. When pre-stretching rate increases to $2 \%$, the rebound rate reaches $0.8 \%$. The initial residual deflection is $3.5 \mathrm{~mm}$, and the residual deflection reduces to $0.55 \mathrm{~mm}$ after $2.5 \%$ pre-stretching, eliminating by $85 \%$.

3) There are different degrees of twinning in surface and center in all deformation rates. When the pre-stretching rate reaches $1 \%$, the tensile strength increases $20 \%$, the yield strength increases $43 \%$ and the fracture elongation decreases $30 \%$. Subsequently, as the increase of pre-stretching rate, the yield strength, tensile strength and elongation changes little.

\section{Acknowledgements}

The authors gratefully acknowledge financial support from NSFC no. 51204020, National Basic Research Program of China no. 2013CB632202 and no. 2013CB632205. 


\section{References}

[1] G.L. SHI, D.F. ZHANG, H.J. ZHANG, X.B. ZHAO, F.G. QI, K. ZHANG, Influence of pre-deformation on age-hardening response and mechanical properties of extruded Mg-6\%Zn-1\%Mnalloy, Trans. Nonferrous Met. Soc. China. 23 (2013) 586-592.

[2] Q.T. JIANG, M.L. MA, K. ZHANG, X.G. LI, Y.J. LI, G.L. SHI, J.W. YUAN, Corrosion behavior of extrusion, under-aged, peaked-aged and over-aged WE93 alloys in $\mathrm{NaHSO}_{3}$ solutions. J Rare Earth. 32(2014) 1170-1174.

[3] J.W. YUAN, Kui ZHANG, X.H. ZHANG, X.G. LI, T. LI, Y.J. LI, M.L. MA, G.L. SHI, Thermal characteristics of $\mathrm{Mg}-\mathrm{Zn}-\mathrm{Mn}$ alloys with high specific strength and high thermal conductivity, J Alloy Compd. 578 (2013) 32-36.

[4] X.S. XIA, Q. CHEN, Z.D. ZHAO, M.L. MA, X.G. LI, K. ZHANG, Microstructure , texture and mechanical properties of coarse-grained $\mathrm{Mg}-\mathrm{Gd}-\mathrm{Y}-\mathrm{Nd}-\mathrm{Zr}$ alloy processed by multidirectional forging, J Alloy Compd. 623 (2015) 62-68.

[5] T. LI, Z.W. DU, K. ZHANG, X.G. LI, J.W. YUAN, Y.J. LI, M.L. MA, G.L. SHI, X. FU, X.L. HAN, Characterisation of precipitates in a Mg-7Gd-5Y-1Nd-0.5Zr alloy aged to peak-ageing plateau, J Alloy Compd. 574 (2013) 174-180. 